\title{
Illicit and abused drugs in sewage sludge: Method optimization and occurrence
}

\author{
Nicola Mastroianni ${ }^{a}$, Cristina Postigo $^{a}$, Miren Lopez de Alda ${ }^{a, *}$, Damia Barcelo $^{a, b}$ \\ a Water and Soil Quality Research Group, Department of Environmental Chemistry, Institute of Environmental Assessment and Water Research \\ (IDAEA-CSIC), C/ Jordi Girona, 18-26, 08034 Barcelona, Spain \\ ${ }^{\mathrm{b}}$ Catalan Institute for Water Research (ICRA), Parc Científic i Tecnològic de la Universitat de Girona, Edifici H2O, Emili Grahit 101, 17003 Girona, Spain
}

\section{A R T I C L E I N F O}

\section{Article history:}

Received 27 August 2013

Received in revised form 21 October 2013

Accepted 24 October 2013

Available online 7 November 2013

\section{Keywords:}

Illicit drugs

Benzodiazepines

Sewage sludge

Analysis

Liquid chromatography-mass spectrometry

\begin{abstract}
A B S T R A C T
A sensitive and reliable method for the determination of 20 abused and illicit drugs and their metabolites in sewage sludge has been developed and validated. To the authors' knowledge, nine out of the 20 selected analytes, namely, cocaethylene, ephedrine, heroin, alprazolam, lysergic acid diethylamide (LSD), its metabolite 2-oxo-3-hydroxy-LSD, and the cannabinoids $\Delta^{9}$-tetrahydrocannabinol (THC), cannabinol ( $\mathrm{CBN})$ and cannabidiol (CBD), are investigated for the first time in this matrix. In the optimized approach, freeze-dried sewage sludge samples were extracted by means of pressurized liquid extraction, and the extracts were further cleaned-up by solid phase extraction. Analytes were determined by liquid chromatography coupled to tandem mass spectrometry. Method limits of quantification were below $3.3 \mathrm{ng} / \mathrm{g}$ d.w. for all compounds but cannabinoids (8.2-22.5 ng/g d.w.). Method repeatability was below $14 \%$ for most compounds. Overall method recoveries were low due to the presence of matrix interferences that could not be completely eliminated and suppressed the ionization of the target analytes between $26 \%$ and $89 \%$. However, extraction losses and matrix effects were satisfactorily corrected through the use of isotopically labeled analogs as surrogate standards, ensuring reliable results. The method was applied to the analysis of various sewage sludge samples. Cannabinoids, methadone and its metabolite 2-ethylidene-1,5-dimethyl-3,3-diphenylpyrrolidine (EDDP) were the most ubiquitous and abundant compounds, showing maximum concentrations above $100 \mathrm{ng} / \mathrm{g} \mathrm{d.w}$. in all cases (up to $579 \mathrm{ng} / \mathrm{g}$ d.w. in the case of THC). This work is the first evidence of the presence of the cannabinoids CBN, CBD, and THC in sewage sludge.
\end{abstract}

(c) 2013 Elsevier B.V. All rights reserved.

\section{Introduction}

In recent years, illicit and abused drugs and their human metabolites have emerged, together with pharmaceuticals and personal care products (PPCPs), as organic pollutants of concern in the environment [1]. Following drug consumption, these compounds are excreted via urine and feces, and, subsequently, mainly collected and pooled by the sewage systems, and transported to wastewater treatment plants (WWTPs) where they can reach ppb levels $[2,3]$. Conventional wastewater treatment processes are not capable of completely removing these compounds, and therefore, they are continuously introduced into the aquatic environment via WWTP effluents [4-6].

To date, a considerable number of analytical methodologies for the analysis of illicit and abused drugs and their metabolites in waters have been developed [7,8], and they have been applied

\footnotetext{
* Corresponding author. Tel.: +34 93400 6100; fax: +34 932045904 .

E-mail address: mlaqam@cid.csic.es (M.L. de Alda).
}

to study the occurrence of these compounds in wastewaters and surface waters [3], groundwaters [9], and even drinking waters [10]. The majority of these studies only took into consideration the amount of compound dissolved in the aqueous phase, whereas only few of them [11-13] also considered the proportion attached to suspended particulate material (SPM). Whereas for most of the investigated drugs this fraction was usually below $5 \%$, values above $10 \%$ were observed for some compounds like methadone (METH), its metabolite 2-ethylidene-1,5-dimethyl-3,3-diphenylpyrrolidine (EDDP), and antidepressant drugs [11].

Data on the occurrence of illicit and abused drugs and their metabolites in sewage sludge are scarce. Senta et al. [13] have recently published the first study in this area covering a broad variety of compounds, 13 in total, belonging to different chemical classes. Before this work, only few of these compounds had been occasionally investigated in sewage sludge, in most cases as part of multi-residue studies that mainly included pharmaceuticals. This was the case for amphetamine (AM) [14,15], methamphetamine (MA) [15,16], 3,4-methylenedioxymethamphetamine (MDMA or ecstasy) [16], cocaine (COC) and its main metabolite 
benzoylecgonine (BE) [15], diazepam (DIA) [15,17,18], and lorazepam $[17,18]$. Levels reported for these compounds in sewage sludge are usually below $100 \mathrm{ng} / \mathrm{g}$ of dry weight (d.w.). However, concentrations up to $300 \mathrm{ng} / \mathrm{g}$ d.w. and $125 \mathrm{ng} / \mathrm{g} \mathrm{d.w}$. were measured for AM [14] and EDDP [13], respectively.

The study of these compounds in particulate material is important because some of them, e.g., $\Delta^{9}$-tetrahydrocannabinol (THC), which is the main psychoactive compound of cannabis which in turn is the most widely used illicit drug [19], and METH and its major metabolite EDDP, present a hydrophobic nature $(\log K o w>3)$ [20], and consequently can be expected to be sorbed onto environmental solid matrices. However, the sorption behavior of organic compounds to environmental matrices is a complex process that may not only depend on hydrophobic interactions, and therefore difficult to predict [21]. Thus, the evaluation of the environmental fate and behavior of illicit drugs and metabolites in solid matrices still depends on chemical analysis.

Sewage sludge produced during wastewater treatment in Europe ( $90 \mathrm{~g}$ d.w. per person per day on average) has been usually used in agriculture or disposed off in landfills, or via incineration [22]. Application of sewage sludge as a soil fertilizer for agricultural purposes constitutes an additional route of entry of organic contaminants to the environment. Therefore, the evaluation of the amount of illicit and abused drugs and their metabolites in sewage sludge is of fundamental importance for the environmental risk assessment of these substances, and, to this end, the development of sensitive and reliable analytical methodologies for their determination in biosolids is essential.

In this context, the main objectives of this work were to develop a multi-residue analytical method based on liquid chromatography-tandem mass spectrometry (LC-MS/MS) detection for trace level determination of the most common illicit and abused drugs and some of their metabolites in sewage sludge, and to apply this method to evaluate the presence of the target compounds in sewage sludge samples. To the authors' knowledge, 9 out of the 20 selected analytes, namely, the cocaine metabolite cocaethylene (CE), ephedrine (EPH), heroin (HER), alprazolam (ALP), lysergic acid diethylamide (LSD), its metabolite 2-oxo-3hydroxy-LSD (OH-LSD), and the cannabinoids THC, cannabinol $(\mathrm{CBN})$ and cannabidiol (CBD), are investigated for the first time in this environmental matrix, providing new knowledge on the presence of illicit drugs in sewage sludge.

\section{Experimental}

\subsection{Chemicals and reagents}

The selected compounds belong to six different chemical classes: cocainics (COC, BE, which is one of $\mathrm{COC}$ main metabolization products, and $\mathrm{CE}$, which is a transesterification product formed when cocaine and alcohol are simultaneously consumed), amphetamine-like compounds (AM, MA, MDMA, $(\mathrm{R}, \mathrm{R})(-)$-pseudoephedrine (PS-EPH), and $(1 \mathrm{~S}, 2 \mathrm{R})(+)$-ephedrine hydrochloride $(\mathrm{EPH}-\mathrm{HCl})$, the last two measured together as total ephedrine (EPH)), opioids (HER, morphine (MOR), 6acetylmorphine (6ACM), which is a hydrolyzed product of heroin, the synthetic opioid METH, and its main metabolite EDDP), benzodiazepines (ALP and DIA), LSD and its metabolite OH-LSD, and cannabinoids (THC, CBD, CBN, and the THC metabolite 11hydroxy-THC (OH-THC)). Main physical-chemical properties and CAS numbers for these compounds are provided as supporting information in Table $\mathrm{S} 1$.

High-purity (>97\%) standard solutions of the target compounds were purchased from Cerilliant (Round Rock, TX, USA) as solutions in methanol $(\mathrm{MeOH})$ or acetonitrile $(\mathrm{ACN})$ at a concentration of
$1 \mathrm{mg} / \mathrm{mL}$ (COC, BE, CE, PS-EPH, EPH-HCl, AM, MA, MDMA, MOR, 6ACM, HER, METH, EDDP, ALP, DIA, LSD, THC, CBD, and CBN) or $0.1 \mathrm{mg} / \mathrm{mL}$ (OH-THC and OH-LSD).

Deuterated analogs for almost all target compounds, used as surrogate standards (SS) for quantitation, were also purchased from Cerilliant (Round Rock, TX, USA) as solutions in $\mathrm{MeOH}$ or ACN at a concentration of $0.1 \mathrm{mg} / \mathrm{mL}$.

Working standard mixtures and calibration solutions were prepared at different concentrations by appropriate dilution of the purchased individual standard solutions in $\mathrm{MeOH}$. All standard solutions were stored in the dark at $-20^{\circ} \mathrm{C}$.

All solvents used (water, $\mathrm{MeOH}$, acetone (ACE) and ACN) were HPLC grade, and were supplied by Merck (Darmstadt, Germany), together with formic acid (98\% purity) and activated neutral aluminum oxide $\left(\mathrm{Al}_{2} \mathrm{O}_{3}\right)\left(99 \%\right.$ purity). Ammonium formate $\left(\mathrm{NH}_{4} \mathrm{HCO}_{2}\right)$ $(>99 \%)$ for mobile phase modification was obtained from Fluka Analytical (St. Louis, MO, USA).

Cellulose filters used in pressurized liquid extraction (PLE) cells were purchased from Dionex Corporation (Sunnyvale, CA, USA). Evolute ABN cartridges ( $50 \mu \mathrm{m}, 200 \mathrm{mg}, 6 \mathrm{cc}$ ) were provided by Biotage (Uppsala, Sweden), and Oasis HLB cartridges (30 $\mu \mathrm{m}$, $200 \mathrm{mg}, 6 \mathrm{cc}$ ) were purchased from Waters Corporation (New Bedford, MA, USA).

Nitrogen gas (99.995\%) was produced by a nitrogen generator system (Centralair, San Sebastian, Spain).

\subsection{Sample collection and pretreatment}

Sewage sludge samples were collected at 15 different WWTPs located along four Mediterranean watersheds in Spain (Llobregat, Ebro, Júcar and Guadalquivir) during autumn 2010. Wastewater treatment in all studied WWTPs is based at least on a preliminary clarification step followed by a biological treatment, which in most cases consists of conventional activated sludge process (CAS). There is one exception in the Ebro River (E3) where biological filters are used instead. The considered WWTPs serve population equivalents between 30,000 and $1,500,000$. Sludge treatment in most of the investigated WWTPs consists of anaerobic digestion followed by centrifuge (belt filter press in the case of WWTP labeled as LL1) thickening and dewatering. As an exception, sludge produced in WWTP E4 is exclusively treated by gravity and centrifuge thickening and dewatering, and afterwards incinerated.

Different grab samples were randomly collected and mixed up at each WWTP providing a final sample weighing approximately $1 \mathrm{~kg}$. Samples were collected at the end of the sewage sludge treatment (after sewage sludge dewatering) using wide-mouth amber glass jars and were maintained at $4{ }^{\circ} \mathrm{C}$ in the dark during transport. Upon arrival to the laboratory, samples were freeze-dried using a LyoAlfa 6-50 freeze-dryer (Telstar S.A., Barcelona, Spain), then finely ground with a mortar and pestle, and stored at $-20^{\circ} \mathrm{C}$ until analysis.

\subsection{Sample extraction and extract cleanup}

Extraction of the target analytes from sewage sludge was performed by pressurized liquid extraction (PLE) using an automated accelerated solvent extractor ASE 200 (Dionex Corporation, Sunnyvale, CA, USA). In the optimized approach, $0.5 \mathrm{~g} \mathrm{~d} . \mathrm{w}$. of freeze-dried sewage sludge were transferred into $11 \mathrm{~mL}$ stainless extraction cells partially filled with $\mathrm{Al}_{2} \mathrm{O}_{3}$ (approximately $5 \mathrm{~g}$, activated at $350{ }^{\circ} \mathrm{C}$ per $\left.15 \mathrm{~min}\right)$. Once in the cell, sewage sludge was spiked with $10 \mathrm{ng}$ of CE- $d_{3}, \mathrm{EPH}-d_{3}, \mathrm{AM}-d_{5}, \mathrm{MA}-d_{14}$, MDMA- $d_{5}, 6 \mathrm{ACM}-d_{6}$, HER- $d_{9}$, EDDP- $d_{3}$, and LSD- $d_{3}$, and 25 ng of COC- $d_{3}$, BE- $d_{3}$, MOR$d_{3}$, METH- $d_{3}$, ALP- $d_{5}$, DIA- $d_{5}$, THC- $d_{3}$, CBD- $d_{3}$, and OH-THC- $d_{3}$, in order to correct for potential losses during the analytical procedure, as well as for matrix effects. Then, void spaces in cells were completely filled up with activated $\mathrm{Al}_{2} \mathrm{O}_{3}$. Two cellulose filters were 
placed at the bottom and at the top of the extraction cells to prevent fine sample particulates leaving the cell and plugging of the system. Optimized PLE conditions were as follows: temperature, $50^{\circ} \mathrm{C}$; pressure, $1250 \mathrm{psi}$; preheating time, heating time, and static time, 5 min each; 1 static cycle; flush volume, $60 \%$; and purge time, $60 \mathrm{~s}$. A mixture of $\mathrm{MeOH} /$ water $(9 / 1, \mathrm{v} / \mathrm{v})$ was used as extraction solvent.

The PLE extract obtained (about $14 \mathrm{~mL}$ ) was evaporated under a gentle stream of $\mathrm{N}_{2}$ with a TurboVap LV evaporator (Zymark, Hopkinton, MA, USA) to an approximate volume of $1.5 \mathrm{~mL}$. Extract was then re-dissolved with HPLC-grade water to a final volume of $25 \mathrm{~mL}$ ( $<1 \%$ of organic content in the re-dissolved extract) for cleanup by means of solid phase extraction (SPE).

In order to increase method sensitivity and reduce matrix interferences, PLE re-dissolved extracts were pre-concentrated onto polymeric Evolute ABN cartridges. SPE was carried out with a Baker vacuum system (J.T. Baker, The Netherlands). Before extract loading, the SPE sorbent was activated and equilibrated with $6 \mathrm{~mL}$ of $\mathrm{MeOH}$ and $6 \mathrm{~mL}$ of $\mathrm{H}_{2} \mathrm{O}$, respectively, through gravity flow (approximately $3 \mathrm{~mL} / \mathrm{min}$ ). Then, the extract was, also gravity assisted, loaded onto the sorbent. After loading completion, the sorbent was washed with $3 \mathrm{~mL}$ of $\mathrm{H}_{2} \mathrm{O}$ and $3 \mathrm{~mL}$ of a mixture of $\mathrm{H}_{2} \mathrm{O} / \mathrm{MeOH}$ $(95 / 5, v / v)$ at gravity flow, and vacuum dried for 15 min prior elution. Analytes were gravity-eluted with $3 \mathrm{~mL}$ of $\mathrm{MeOH}$ and $3 \mathrm{~mL}$ of $\mathrm{MeOH} /$ formic acid (99/1, v/v). Both elution fractions were collected in the same vial, then evaporated to dryness with a PIERCE ReactiTherm III evaporator (Rockford, IL, USA), and finally reconstituted with $0.5 \mathrm{~mL}$ of $\mathrm{MeOH}$ prior to LC-MS/MS analysis.

\subsection{LC-ESI-(QqLIT)MS/MS analyses}

Analyses were performed with a HPLC Symbiosis ${ }^{\mathrm{TM}}$ Pico System (Spark Holland, Emmen, The Netherlands) connected in series with a 4000QTRAP hybrid triple quadrupole-linear ion trap (QqLIT) mass spectrometer equipped with a Turbo Ion Spray source (Applied Biosystems-Sciex, Foster City, CA, USA) operating in positive ionization mode (ESI+). The LC-MS/MS method used for the analysis of the target compounds in the sewage sludge extracts is a variation of a previously described method [23]. Main modifications included in the method were:

1. the addition of the benzodiazepines ALP and DIA, and the cannabinoids CBD and CBN into the list of target compounds, together with the corresponding deuterated analogs for isotope dilution quantification,

2. the addition of modifiers to the mobile phase to decrease and maintain its $\mathrm{pH}$ at 3.8, which aids in decreasing chromatographic peak tailing and improving compound ionization, and

3. the use of MS positive electrospray ionization for all target analytes.

Chromatographic separation was achieved with a Purospher Star RP-18 end-capped column $(125 \mathrm{~mm} \times 2.0 \mathrm{~mm}$, particle size $5 \mu \mathrm{m})$ preceded by a guard column of the same packing material, both from Merck (Darmstad, Germany), and a binary mobile phase consisting of ACN and water containing $20 \mathrm{mM}$ of formic acid/ammonium formate buffer ( $\mathrm{pH} 3.8$ ) at a constant flow rate of $0.3 \mathrm{~mL} / \mathrm{min}$. The proportion of the organic solvent during the chromatographic run was as follows: $0 \mathrm{~min}-5 \%, 12 \mathrm{~min}-40 \%, 18 \mathrm{~min}$ $-70 \%, 19 \min -80 \%, 26 \min -100 \%, 28 \min -100 \%$, $30 \min -5 \%$, $40 \mathrm{~min}-5 \%$.

For quantitative analysis, data acquisition was performed in selected reaction monitoring (SRM) mode, recording the SRM transitions between the precursor ion and the two most abundant product ions for each target analyte. Optimum SRM transitions and ionization conditions for the new deuterated and target compounds were obtained by direct injection of their individual standard solutions in $\mathrm{MeOH}$ at an approximate concentration of $500 \mathrm{ng} / \mathrm{mL}$. Retention times and selected MS/MS detection conditions are shown as supporting information in Table S2.

\subsection{Method validation}

The performance of the methodology was evaluated in terms of linearity, sensitivity, recovery, repeatability, and matrix effects. In the absence of method validation guidelines for organic emerging contaminants in sludge, validation was performed according to the guidelines set for pesticide residues analysis in food and feed (SANCO/12495/2011) [24].

Quantification was performed by the internal standard (IS) method, based on the peak areas obtained for the analyte and its deuterated analog. Deuterated compounds were added to calibration solutions (and to samples) as surrogate standards (see Section 2.3). Eleven-point calibration curves were constructed, using least squares linear regression analysis, by injecting standard solutions prepared in methanol in the concentration range from $0.1 \mathrm{ng} / \mathrm{mL}$ (or the limit of quantification if higher) to $1000 \mathrm{ng} / \mathrm{mL}$ (equivalent to 0.1 and $1000 \mathrm{ng} / \mathrm{g}$ d.w., respectively).

The method limits of detection (LODs) and quantification (LOQs) were experimentally estimated from the PLE-SPE-LC-MS/MS analysis of sewage sludge samples as the concentration of analyte giving a signal-to-noise ratio of 3 and 8, respectively. Due to the heterogeneity of the investigated matrix, the reported values correspond to the average of the LODs and LOQs calculated in each positive sample for any given compound. When the target compound was not detected in any of the analyzed samples, LODs and LOQs were obtained from the $\mathrm{S} / \mathrm{N}$ values observed in the recovery study carried out at the lowest level of fortification ( $50 \mathrm{ng} / \mathrm{g} \mathrm{d.w.,} n=5$ ).

Recoveries for the analytical method developed were calculated from replicate analysis $(n=5)$ of fortified sewage sludge at two different concentrations, 50 and $100 \mathrm{ng} / \mathrm{g}$ d.w. Recoveries at the LOQ could not be carried out due to the background contamination with the target analytes of the sludge available for method validation. Absolute recoveries were calculated by comparing the analyte peak area obtained in fortified samples (after subtracting the amount of the analyte in the blank $(n=3)$, if present) and in standard solutions with equivalent concentrations. Relative recoveries were calculated by comparing the absolute recoveries obtained for each compound and its associated surrogate standard (spiked at 20 or $50 \mathrm{ng} / \mathrm{g} \mathrm{d.w}$. as indicated in Section 2.3).

Overall, method repeatability for each analyte was calculated as the relative standard deviation (RSD) of the peak areas obtained after the replicate $(n=5)$ analysis of a sewage sludge sample fortified at $50 \mathrm{ng} / \mathrm{g}$ d.w. and at $100 \mathrm{ng} / \mathrm{g}$ d.w. with the standard mixture.

Matrix effects were evaluated by comparing the peak area obtained for each compound in a sewage sludge extract fortified at the end of the sample treatment procedure, i.e., after the PLE and SPE steps, ( $A_{\text {sludge }}$ ) (after subtracting the amount of the analyte in the blank if present $\left.\left(A_{\text {blank }}\right)\right)$, and in a standard solution at equivalent concentration $\left(A_{\text {std }}\right)(100 \mathrm{ng} / \mathrm{mL}$, equivalent to $100 \mathrm{ng} / \mathrm{g}$ d.w.). According to the following equation: $\left(\left(\left(A_{\text {sludge }}-A_{\text {blank }}\right)-A_{\text {std }}\right) / A_{\text {std }}\right) \times 100$, if the value obtained is positive, the analyte MS signal is enhanced by matrix components, whereas if the value obtained is negative, the ionization of the analyte is being suppressed. Values close to 0 indicate the absence of matrix effects.

\section{Results and discussion}

\subsection{Sample extraction and cleanup}

According to the peer-reviewed literature, extraction of illicit drugs and metabolites from environmental solid matrices has 
a)

$\mathrm{MeOH} /$ water $(1 / 1, \mathrm{v} / \mathrm{v}) \quad \square \mathrm{MeOH} /$ water $(9 / 1, \mathrm{v} / \mathrm{v}) \quad \mathbf{\Delta} \mathrm{MeOH}$

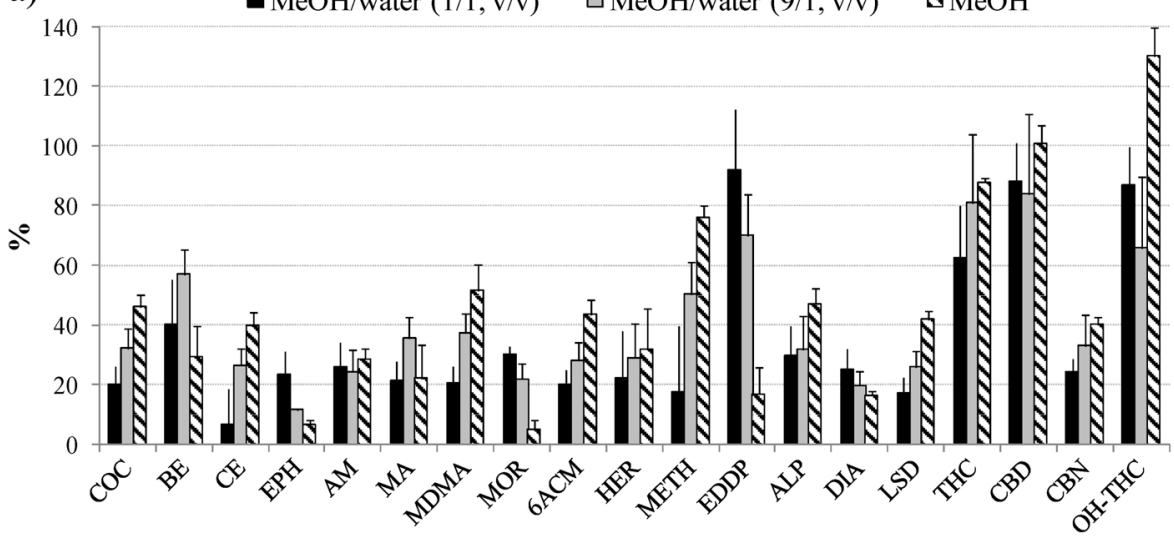

b) $\quad 50^{\circ} \mathrm{C} \quad \square 100^{\circ} \mathrm{C}$

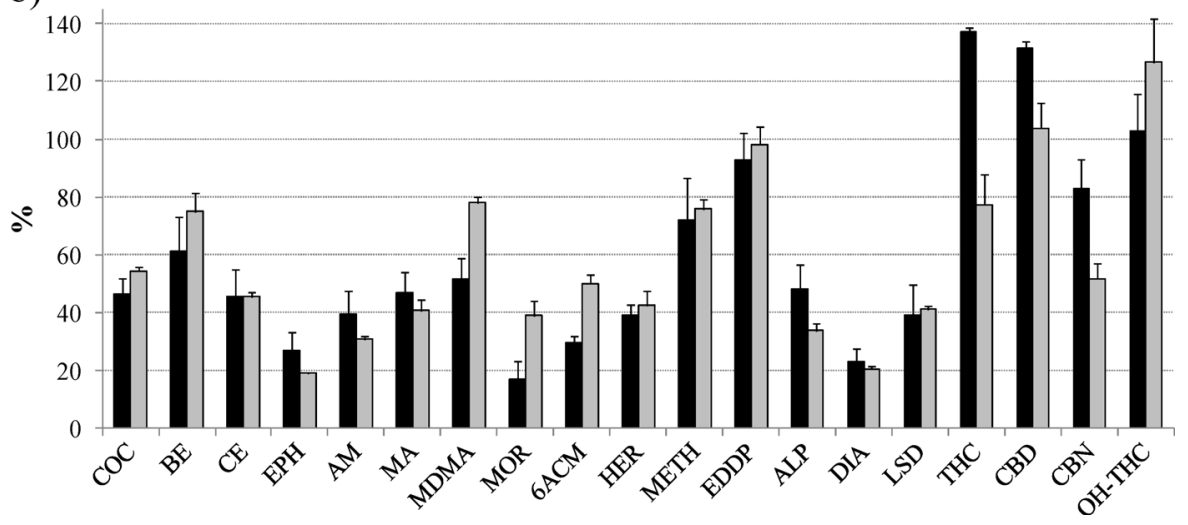

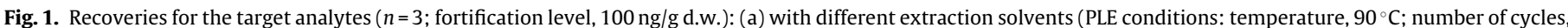

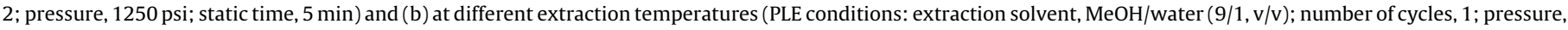
1250 psi; static time, $5 \mathrm{~min}$ ).

been usually carried out by means of PLE $[11,13,15,16]$ and ultrasonic extraction (USE) based methods [12,14]. In this work, PLE was selected over USE because of its automation, lower solvent consumption, and the possibility of performing an initial in-cell clean-up by adding an appropriate sorbent material to the extraction cell. In our approach, activated alumina was used for this purpose in order to prevent an undesired extraction of lipids.

Since sewage sludge is a very complex matrix and large amounts of compounds are co-extracted during PLE, an additional clean-up of the PLE extract based on SPE was included in the analytical methodology in order to get rid of matrix interferences. SPE has been also the technique of choice to clean-up sewage sludge extracts in the previously published works [13-16], with the single exception of Jones Lepp et al. [16], who applied hexane washes.

Both PLE and SPE processes were optimized as described in the next sections in order to obtain the best method performance for all target analytes.

\subsubsection{PLE optimization}

In the optimization of a PLE method, the extraction solvent and the extraction temperature are the two most important parameters to consider. In this work, these key parameters together with the number of cycles were extensively investigated. Other extraction parameters, like pressure, static time, purge time and flush volume, were set in accordance with a previously developed PLE protocol for analysis of illicit drugs and metabolites in atmospheric particulate [25].

PLE recoveries during method development were calculated by comparing peak areas obtained after analysis in triplicate of sewage sludge samples $(0.5 \mathrm{~g}$ d.w.) fortified with $50 \mathrm{ng}$ of the compounds before the PLE step and a standard solution at equivalent concentration $(100 \mathrm{ng} / \mathrm{mL})$. OH-LSD was the only analyte not included in the PLE optimization tests because it was purchased at a later stage. However, it was included in the validation of the final method.

As an starting point, a sequential extraction with $\mathrm{MeOH}$ and $\mathrm{MeOH} / \mathrm{ACE}(1 / 1, \mathrm{v} / \mathrm{v})$ was tested [25]. Under these conditions (data not shown), BE, the amphetamine-like compounds EPH and MA, HER, and EDDP were poorly recovered (<17\%). According to the peer-reviewed literature, different mixtures of $\mathrm{MeOH} /$ water $[15,17]$, sometimes acidified $[11,13,14,16]$, have been commonly used to extract illicit drugs and pharmaceuticals from solid environmental samples. Therefore, in order to improve the recovery of the above mentioned compounds and reduce the amount of coextracted matrix components, the extraction efficiency of $\mathrm{MeOH}$ and other more polar mixtures of solvents, e.g., different mixtures of $\mathrm{MeOH} /$ water $(1 / 1$ and $9 / 1, \mathrm{v} / \mathrm{v})$, was evaluated, and the results obtained are given in Fig. 1a. In the light of the results, two extraction cycles with $\mathrm{MeOH}$ provided the highest average recoveries for 12 of the 19 investigated analytes; however, the addition of water clearly improved the extraction of those compounds poorly recovered with $\mathrm{MeOH}$, i.e., $\mathrm{BE}, \mathrm{EPH}, \mathrm{MOR}$, EDDP, and DIA, and reduced the amount of co-extracted matrix components.

Most PLE procedures for the extraction of abused and illicit drugs from solid environmental samples operate between $50^{\circ} \mathrm{C}$ and $100^{\circ} \mathrm{C}[11,13,15,16,21,25,26]$. High temperature can improve extraction efficiency by decreasing viscosity and surface tension of the solvent; however, it may also degrade thermally labile compounds and/or decrease the extraction selectivity, co-extracting undesired matrix interfering components. In this work, recoveries at $50^{\circ} \mathrm{C}$ and $100^{\circ} \mathrm{C}$ were tested. Results are summarized in Fig. $1 \mathrm{~b}$. 
Table 1

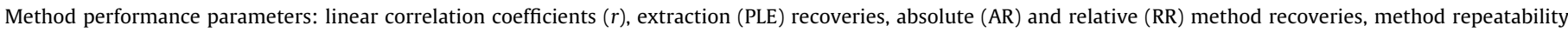
(RSD), matrix effects, and method limits of detection (LOD) and quantification (LOQ) for the various analytes in sewage sludge.

\begin{tabular}{|c|c|c|c|c|c|c|c|c|}
\hline & \multirow{2}{*}{$\begin{array}{l}\text { Linearity }^{\mathrm{a}} \\
r\end{array}$} & \multirow{2}{*}{$\begin{array}{l}\text { PLE recovery } \\
(\%)\end{array}$} & \multicolumn{2}{|c|}{ Method recovery } & \multirow{2}{*}{$\begin{array}{l}\text { Repeatibility }^{\mathrm{b}} \\
\text { RSD (\%) }\end{array}$} & \multirow{2}{*}{$\begin{array}{l}\text { Matrix Effect } \\
(\%)\end{array}$} & \multirow{2}{*}{$\begin{array}{l}\text { LOD } \\
\text { ng/g d.w. }\end{array}$} & \multirow{2}{*}{$\begin{array}{l}\text { LOQ } \\
\text { ng/g d.w. }\end{array}$} \\
\hline & & & AR (\%) & RR (\%) & & & & \\
\hline $\mathrm{COC}$ & 1.0000 & 85 & $45 / 41$ & $97 / 101$ & $3 / 5$ & -50 & 0.2 & 0.5 \\
\hline $\mathrm{COC}-\mathrm{d}_{3}$ & & & 43 & & 7 & & & \\
\hline $\mathrm{BE}$ & 0.9999 & 82 & $45 / 43$ & $103 / 93$ & $11 / 4$ & -51 & 0.2 & 0.6 \\
\hline$B E-d_{8}$ & & & 39 & & 5 & & & \\
\hline $\mathrm{CE}$ & 0.9920 & 83 & $43 / 40$ & $100 / 97$ & $3 / 4$ & -53 & 0.2 & 0.5 \\
\hline$C E-d_{3}$ & & & 43 & & 7 & & & \\
\hline EPH & 0.9998 & 94 & $40 / 36$ & $104 / 101$ & $3 / 2$ & -48 & 0.4 & 1.0 \\
\hline $\mathrm{EPH}-d_{3}$ & & & 34 & & 13 & & & \\
\hline $\mathrm{AM}^{\mathrm{c}}$ & 0.9985 & 82 & 41 & 129 & 7 & -26 & 0.4 & 1.3 \\
\hline AM- $d_{5}$ & & & 51 & & 11 & & & \\
\hline MA & 0.9994 & 73 & $47 / 39$ & $98 / 94$ & $3 / 4$ & -38 & 0.5 & 1.6 \\
\hline MA- $d_{14}$ & & & 46 & & 16 & & & \\
\hline MDMA & 0.9992 & 77 & $53 / 49$ & $97 / 101$ & $5 / 5$ & -33 & 0.1 & 0.3 \\
\hline MDMA- $d_{5}$ & & & 51 & & 9 & & & \\
\hline MOR & 0.9996 & 41 & $30 / 25$ & $116 / 112$ & $12 / 13$ & -40 & 2.5 & 3.3 \\
\hline MOR- $d_{3}$ & & & 28 & & 11 & & & \\
\hline $6 A C M$ & 0.9968 & 113 & $63 / 63$ & $97 / 105$ & $2 / 4$ & -49 & 0.7 & 2.6 \\
\hline $6 \mathrm{ACM}-d_{6}$ & & & 61 & & 7 & & & \\
\hline HER & 0.9991 & 32 & $13 / 18$ & $93 / 116$ & $14 / 19$ & -54 & 1.4 & 2.0 \\
\hline HER- $d_{9}$ & & & 15 & & 17 & & & \\
\hline METH & 0.9998 & 83 & $36 / 33$ & $98 / 99$ & $4 / 3$ & -62 & 0.2 & 0.3 \\
\hline METH- $d_{3}$ & & & 36 & & 10 & & & \\
\hline $\mathrm{EDDP}^{\mathrm{c}}$ & 0.9982 & 61 & 47 & 110 & 8 & -59 & 0.1 & 0.3 \\
\hline EDDP- $d_{3}$ & & & 44 & & 11 & & & \\
\hline DIA & 0.9986 & 79 & $17 / 14$ & $92 / 89$ & $10 / 6$ & -80 & 0.2 & 0.5 \\
\hline DIA- $d_{5}$ & & & 19 & & 12 & & & \\
\hline ALP & 0.9993 & 84 & $26 / 24$ & $103 / 100$ & $6 / 3$ & -73 & 0.1 & 0.3 \\
\hline ALP- $d_{5}$ & & & 26 & & 9 & & & \\
\hline LSD & 0.9996 & 87 & $40 / 36$ & $95 / 105$ & $4 / 3$ & -55 & 0.1 & 0.4 \\
\hline LSD- $d_{3}$ & & & 38 & & 9 & & & \\
\hline OH-LSD & 0.9993 & 61 & $16 / 21$ & $55 / 88$ & $5 / 6$ & -68 & 0.3 & 0.8 \\
\hline $\mathrm{THC}^{\mathrm{c}}$ & 1.0000 & 94 & 5 & 130 & 9 & -89 & 3.1 & 8.2 \\
\hline THC- $d_{3}$ & & & 8 & & 12 & & & \\
\hline $\mathrm{CBD}^{\mathrm{c}}$ & 0.9980 & 91 & 13 & 99 & 9 & -80 & 3.5 & 9.3 \\
\hline CBD- $d_{3}$ & & & 13 & & 3 & & & \\
\hline $\mathrm{CBN}^{\mathrm{C}}$ & 0.9995 & 94 & 10 & 127 & 8 & -84 & 6.0 & 22.5 \\
\hline $\mathrm{OH}-\mathrm{THC}^{\mathrm{C}}$ & 1.0000 & 85 & 20 & 115 & 5 & -67 & 6.4 & 17.1 \\
\hline $\mathrm{OH}-\mathrm{THC}-d_{3}$ & & & 23 & & 16 & & & \\
\hline
\end{tabular}

a Calibration curve range: 0.1 (or the LOQ if higher) - $1000 \mathrm{ng} / \mathrm{mL}$ in methanol (equivalent to $0.1-1000 \mathrm{ng} / \mathrm{g}$ d.w.).

b Calculated at 50 and $100 \mathrm{ng} / \mathrm{g}$ d.w. (corresponding values separated by “/”)

c Calculated at $1000 \mathrm{ng} / \mathrm{g}$ d.w. due to high background levels of the compounds in the sludge sample.

At $100^{\circ} \mathrm{C}$, the extraction of MDMA, MOR and 6ACM was increased in $51 \%, 131 \%$ and $70 \%$, respectively. However, a negative effect was observed on the extraction of EPH (-29\%), AM (-21\%), ALP $(-30 \%)$, THC (-43\%), CBD $(-21 \%)$ and CBN $(-37 \%)$. In this respect, the achievement of better recoveries for cannabinoids and most of the amphetamine-like compounds at $50^{\circ} \mathrm{C}$, as well as the gain of a cleaner PLE extract, in terms of extract appearance and color, motivated the selection of the lower extraction temperature.

Finally, the optimum number of extraction cycles was evaluated by multiple sequential extractions of fortified sludge samples $(n=3)$. The amount of analyte recovered after each cycle was expressed as a percentage of the maximum extractable amount, which was defined as the sum of the amount recovered during the three extraction cycles. As can be observed in Fig. S1, with the exception of MOR, all analytes were recovered above $77 \%$ during the first extraction cycle. Contributions of the second and third cycles to the total extractable amounts were below $17 \%$ and $5 \%$, respectively. Surprisingly, in the case of MOR, the second and the third extraction cycles, contributed with $54 \%$ and $22 \%$ to the maximum extractable amount, which suggests a particular behavior of MOR within the solid phase. MOR and HER showed also an abnormal behavior during batch sorption experiments carried out by Barron et al. [21], which was attributed to still non-elucidated fast transformation pathways of MOR and HER within the solid phase. In this respect, the use of isotopically labeled analogs for the analysis of these compounds is solid matrices is required to ensure data reliability. In the light of the results, two extraction cycles would allow recovering most of the extractable amount of the analytes from the sewage sludge; however, the performance of a second extraction cycle would increase the amount of unwanted co-extracted matrix material, and thus the matrix interferences, as well as the time required to evaporate the PLE extract, which could also negatively affect the performance of the method. Therefore, taking into account the multi-residue character of this methodology, one extraction cycle was considered as the best compromise for the analysis of all selected compounds.

The performance of the optimized PLE procedure was evaluated in triplicate by analyzing sewage sludge samples fortified at $100 \mathrm{ng} / \mathrm{g}$ d.w. before the PLE process, and unspiked sewage sludge PLE extracts fortified at $100 \mathrm{ng} / \mathrm{mL}$ before the SPE step. In this way, PLE recoveries can be decoupled from SPE performance and matrix effects. PLE recoveries, summarized in Table 1, were between $61 \%$ (EDDP and OH-LSD) and 113\% (6ACM) for all analytes but MOR and HER, for which only $41 \%$ and $32 \%$ could be recovered. RSD values were below $21 \%$ in all cases.

\subsubsection{SPE optimization}

Two different polymer-based sorbents, namely Oasis HLB and Evolute $A B N$, were evaluated for extract purification. Both cartridges are designed for the simultaneous extraction of a wide range 


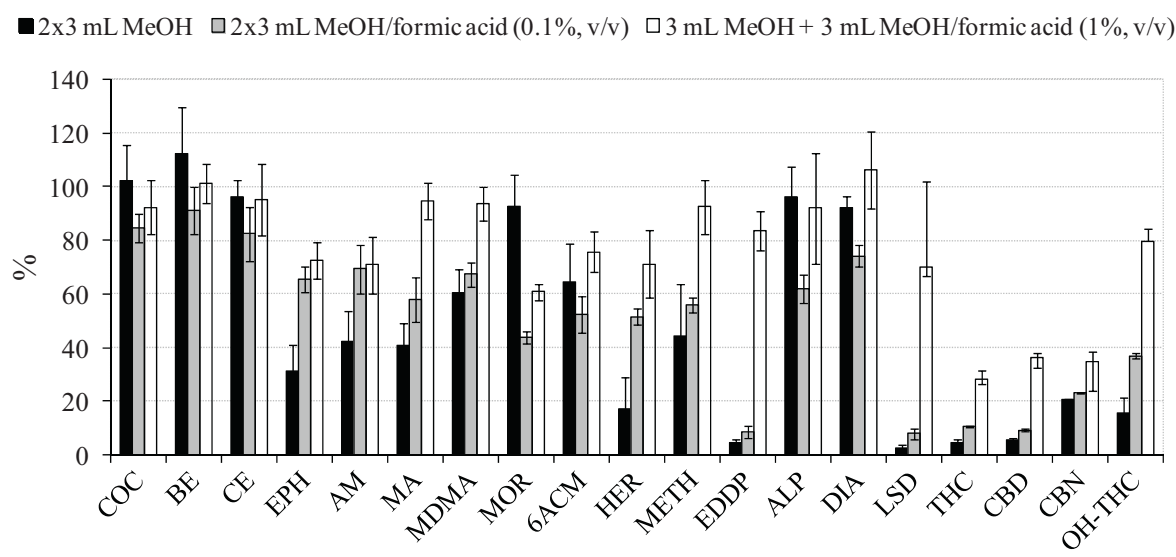

Fig. 2. SPE recovery for the target analytes ( $n=3$, HPLC-grade water fortified at $2 \mathrm{ng} / \mathrm{mL}$ ) with different elution solvents.

of acidic, basic, and neutral compounds, and Oasis HLB cartridges in particular, have been widely used to extract and concentrate illicit drugs and pharmaceuticals from liquid and solid environmental samples $[14,17,27,28]$.

Sorbent performance was evaluated by extracting $25 \mathrm{~mL}$ of HPLC-grade water fortified with $50 \mathrm{ng}$ of the target analytes using a general extraction approach. Briefly, the sorbent was conditioned with $6 \mathrm{~mL}$ of $\mathrm{MeOH}$, equilibrated with $6 \mathrm{~mL}$ of $\mathrm{H}_{2} \mathrm{O}$, loaded with the sample, washed with $6 \mathrm{~mL}$ of $\mathrm{H}_{2} \mathrm{O}$, and vacuum dried for $15 \mathrm{~min}$. Elution was performed with $6 \mathrm{~mL}$ of $\mathrm{MeOH}$. The eluate was evaporated to dryness and reconstituted with $0.5 \mathrm{~mL}$ of $\mathrm{MeOH}$ for LC-MS/MS analysis. Recoveries obtained with both sorbents, calculated by comparing the peak areas obtained for each analyte in the SPE extracts and in a standard solution at an equivalent concentration, were rather similar for most of the target compounds (data shown as supporting information in Fig. S2). However, Evolute $A B N$ cartridges were finally selected because they provided comparatively higher recoveries for a larger number of compounds, and among them HER and EDDP, which were hardly recovered with the Oasis HLB cartridges.

For elution $\mathrm{MeOH}(2 \times 3 \mathrm{~mL}), \mathrm{MeOH}$ acidified with formic acid $(0.1 \%, v / v)(2 \times 3 \mathrm{~mL})$, and a combination $\mathrm{MeOH}$ and acidified $\mathrm{MeOH}$ ( $3 \mathrm{~mL} \mathrm{MeOH}$ followed by $3 \mathrm{~mL} \mathrm{MeOH}$ with $1 \%$ formic acid) were investigated. The results are summarized in Fig. 2. Of all three tested conditions, the latter provided the best results, since the use of acidified $\mathrm{MeOH}$ after pure $\mathrm{MeOH}$ helped increase the recovery of otherwise poorly eluted compounds like EPH, AM, MA, HER, and most cannabinoids. This SPE approach allowed recoveries between $61 \%$ (MOR) and 106\% (DIA) for all analytes except the cannabinoids THC, CBD, and CBN, for which only $28 \%, 35 \%$ and $36 \%$ could be recovered. RSD values for all analytes were below $22 \%$.

\section{2. $L C-M S / M S$ analyses}

Cannabinoids are, among the various target analytes, the only ones amenable to both negative [29] and positive [27,30,31] electrospray ionization analysis. Despite the fact that negative ionization provides a slightly better response for cannabinoids compared to positive ionization, the latter was chosen in the present study in order to analyze all target compounds in the same analytical run, and reduce analysis time and analytical consumables. In order to maximize the cannabinoids signal under positive ionization, data acquisition was performed under time-scheduled conditions: during the first period, which runs for the first $18 \mathrm{~min}$ of the chromatographic run, all target analytes but cannabinoids were monitored, and during the second period, which corresponds with the elution of the cannabinoids from the chromatographic column, only the SRM transitions selected for the analysis of the target cannabinoids were registered (see Table S2 in supporting information). This allows increasing the dwell time, and consequently the signal to noise ratio $(\mathrm{S} / \mathrm{N})$ and the sensitivity achieved for the cannabinoids, while maintaining the peak area reproducibility.

Method selectivity is provided by the monitoring of two SRM transitions per compound, thus achieving the four identification points required by the EU legislation for reliable identification of organic residues in food, also extendable to environmental samples [32]. Analyte confirmation criteria were in agreement with EU legislation [32].

\subsection{Method validation}

The performance of the method was evaluated in terms of linearity, sensitivity, analyte recovery, repeatability, and matrix effects, as described in Section 2.5. Method performance data are provided in Table 1. Extracted ion chromatograms obtained after PLE-SPE-LC-MS/MS analysis of a sewage sludge sample fortified at $50 \mathrm{ng} / \mathrm{g}$ d.w. with the target analytes is shown as supporting information in Fig. S3.

Response of the MS signal between $0.1 \mathrm{ng} / \mathrm{mL}$ or the analyte limit of quantification if higher and $1000 \mathrm{ng} / \mathrm{mL}$ (equivalent to $0.1 \mathrm{ng} / \mathrm{g}$ d.w. and $1000 \mathrm{ng} / \mathrm{g}$ d.w.) was linear for all analytes, obtaining correlation coefficients $(r)$ above 0.99 with nine or more data points.

Most of the compounds exhibited average LODs and LOQs lower than 2.5 and $3.3 \mathrm{ng} / \mathrm{g}$ d.w., respectively. Average LOQs for cannabinoids were slightly higher, between 8.2 and $22.5 \mathrm{ng} / \mathrm{g}$ d.w.

Recoveries of the overall PLE-SPE-LC-MS/MS method were calculated by analyzing sewage sludge samples $(n=5)$ fortified at two concentration levels (50 and $100 \mathrm{ng} / \mathrm{g} \mathrm{d.w.)} \mathrm{Relevant} \mathrm{amounts} \mathrm{of}$ AM (120 ng/g d.w.), EDDP (41 ng/g d.w.), THC (114 ng/g d.w.), CBD (111 ng/g d.w.), CBN (47 ng/g d.w.), and OH-THC (40 ng/g d.w.) were found to be present in the matrix available for method validation, and therefore, recovery experiments for these compounds were performed at an approximately 10 -fold higher concentration (1000 ng/g d.w.). As it can be observed in Table 1, absolute and relative recoveries of the method observed at $50 \mathrm{ng} / \mathrm{g}$ d.w. were, in general, in good agreement with those obtained at $100 \mathrm{ng} / \mathrm{g} \mathrm{d.w}$. The lowest overall method recoveries were observed for cannabinoids THC, CBD and CBN (5-13\%); however, extraction losses can be well compensated by the addition of deuterated surrogates as indicated by relative recoveries values. Note that the extraction recovery of $\mathrm{OH}-\mathrm{THC}(20 \%)$ is in good agreement with that reported by Senta et al. (24\%), who also included this cannabinoid in their study [13]. Absolute recoveries for cocainics and amphetaminelike compounds (36-53\%) were also in good agreement with those reported by Senta et al. for this type of analytes in the particulate phase of sewage sludge (40-59\%) [13]. The highest variations in 


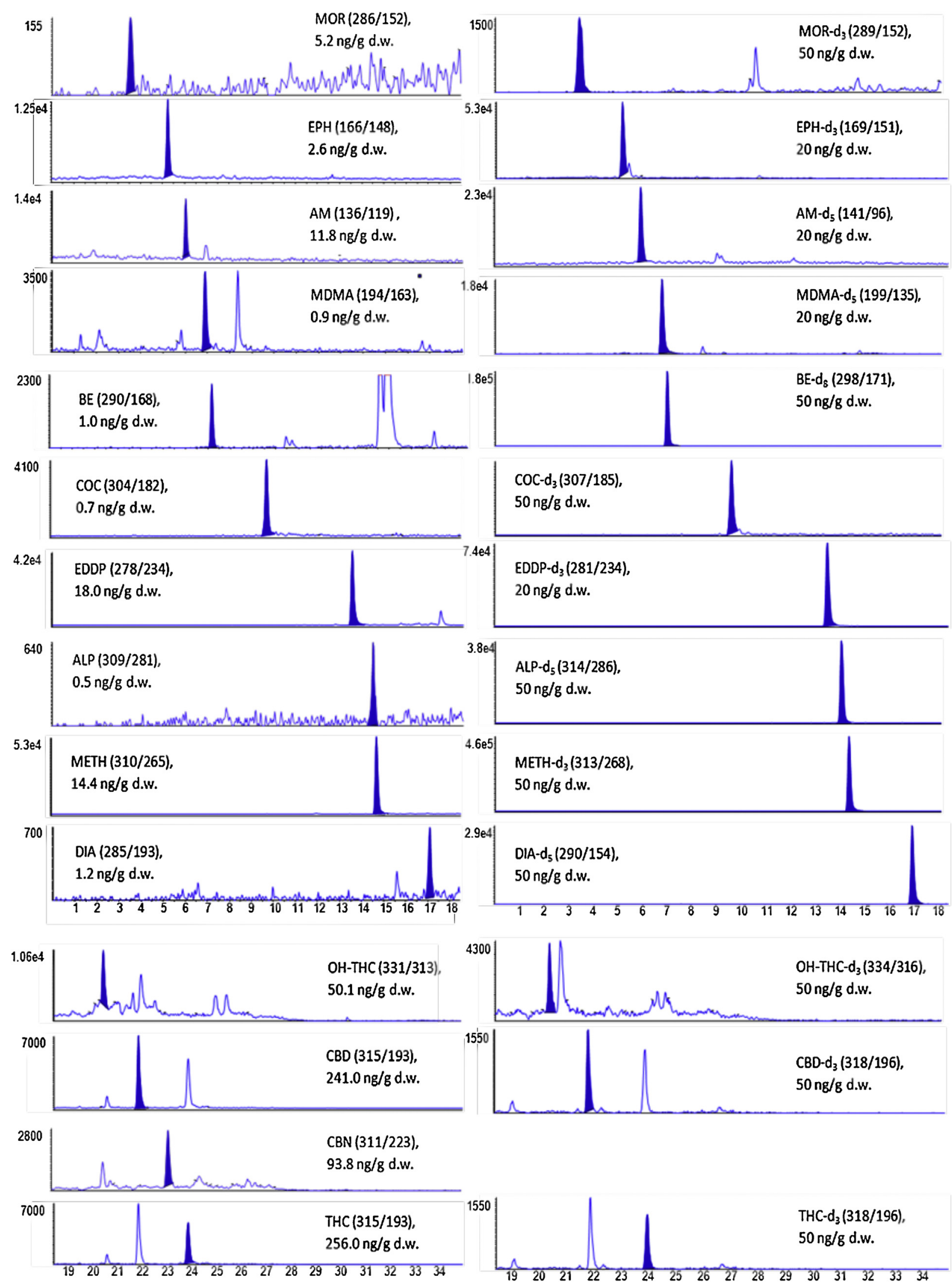

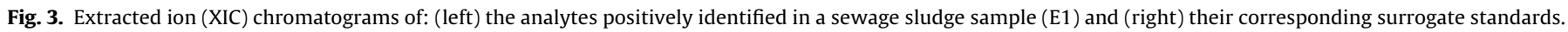


Table 2

Frequency of detection (\%) and median and concentration range (in ng/g d.w.) of the compounds found to be present in the investigated sewage sludge samples.

\begin{tabular}{lrcc}
\hline \multirow{2}{*}{ Compound } & Freq. (\%) $n=15$ & \multicolumn{2}{c}{ Concentration (ng/g d.w.) } \\
\cline { 3 - 4 } & & Median & Range \\
\hline COC & 93 & 2.0 & $0.7-23.0$ \\
BE & 40 & 1.3 & $0.8-3.2$ \\
CE & 7 & 0.7 & - \\
EPH & 80 & 2.9 & $0.6-44.1$ \\
AM & 47 & 6.6 & $2.1-13.9$ \\
MA & 27 & 0.2 & - \\
MDMA & 60 & 0.9 & $0.4-2.7$ \\
MOR & 47 & 5.5 & $2.2-19.1$ \\
METH & 100 & 15.9 & $6.7-111.0$ \\
EDDP & 100 & 45.6 & $8.7-279.0$ \\
ALP & 60 & 0.6 & $0.5-1.9$ \\
DIA & 73 & 2.2 & $0.6-2.5$ \\
THC & 100 & 138.0 & $29.9-579.0$ \\
CBD & 80 & 168.0 & $32.2-479.0$ \\
CBN & 53 & 100.9 & $26.7-188.0$ \\
OH-THC & 67 & 78.4 & $10.3-160.0$ \\
\hline
\end{tabular}

extraction recoveries were found within the opioids group. 6ACM presented the best extraction recovery of all investigated analytes (63\%), whereas HER was poorly extracted (13-18\%). MOR was recovered on average $25-30 \%$. Contrary to our findings, Senta et al. reported $10 \%$ and $69 \%$ of extraction recovery for 6ACM and MOR, respectively [13]. Apart from the analytical conditions used, this could be related to a special behavior of opioids in the solid phase, as suggested by Barron et al. [21]. The overall recovery of target benzodiazepines was below $26 \%$, and that of LSD (36-40\%) was above the extraction recovery of its metabolite OH-LSD (16-21\%).

These low recoveries and the nature of such a complex matrix require the use of isotopically labeled analogs as surrogate standards, in order to achieve reliable results. Relative recoveries of the target analytes with respect to their deuterated analogs were in the range of $89-130 \%$, with the only exception of OH-LSD, which showed a slightly higher deviation (55\% at samples fortified at $50 \mathrm{ng} / \mathrm{g}$ d.w.), since no deuterated analog for this compound was available. Method repeatability was satisfactory with RSD values in all cases below $20 \%$.

All target compounds were subject to matrix ionization suppression effects. As shown in Table 1, a signal drop between 26\% (AM) and $89 \%$ (THC) was observed. Cannabinoids and benzodiazepines were the most affected compounds. By contrast, the lowest drop in the analytical signal was observed for amphetamine-like compounds. Again, considering the high matrix effects observed in the analysis of this type of samples, the use of isotopically marked compounds for quantification is crucial.

\subsection{Occurrence of target analytes in sewage sludge samples}

The analytical methodology developed was applied to the analysis of 15 treated sewage sludge samples collected from various WWTPs located along four Spanish river basins. Table 2 collects the frequency of detection, the concentration range, and the median concentration of the compounds positively identified in the samples. Detailed results are shown as supporting information in Table S3.

The most ubiquitous compounds were METH, EDDP, and THC, which were present in all samples, followed by COC, EPH and CBD, present in at least $80 \%$ of the samples. On the contrary, the opioids HER and 6ACM, and LSD and its metabolite OH-LSD were not detected in any sample.

The most abundant compounds were the cannabinoids, with median concentrations ranging between 78.4 and $168.0 \mathrm{ng} / \mathrm{g}$ d.w. (see Table 2). The most psychoactive cannabinoid, THC, reached up to $579.0 \mathrm{ng} / \mathrm{g}$ d.w. in one of the samples collected at the Guadalquivir River basin (G3). This sample also presented the highest levels of CBD, CBN and OH-THC (see Table S3). Overall, the levels of OH-THC measured in the collected samples were one order of magnitude higher than those reported by Senta et al. in particulate (sewage sludge and suspended solids) [13].

In terms of abundance, cannabinoids were followed by the synthetic opioid METH and its metabolite EDDP, which presented median concentrations of $15.9 \mathrm{ng} / \mathrm{g}$ d.w. and $45.6 \mathrm{ng} / \mathrm{g}$ d.w., respectively. Maximum values found in this study for METH and EDDP were higher than those reported by Senta et al. in the particulate phase of activated sewage sludge samples; however, similar overall concentrations were observed [13]. The natural opiate MOR, not detected in the particulate phase of activated sewage sludge by Senta et al. [13], was positively identified in less than $50 \%$ of the samples analyzed in the present study, and at levels below $19.1 \mathrm{ng} / \mathrm{g}$ d.w.

COC was also frequently detected (93\% of samples positive) and presented median ( $2 \mathrm{ng} / \mathrm{g}$ d.w.) and maximum concentrations (23 ng/g d.w.) above those observed for its metabolites BE and CE, which were also less ubiquitous than COC ( $40 \%$ and $7 \%$ of positive samples, respectively). These findings are in agreement with the polar character of $\mathrm{BE}$ and the lower concentrations of $\mathrm{CE}$ found in wastewaters as compared to the parent compound [3]. Levels of $\mathrm{COC}$ and $\mathrm{BE}$ in sludge samples from Croatia and Scotland were below $5 \mathrm{ng} / \mathrm{g}$ d.w., and below the method LOD (5-20 ng/g d.w.), respectively [15].

EPH was not only the most detected amphetamine-like compound, being present in $80 \%$ of the samples, but also the most abundant, reaching up to $44 \mathrm{ng} / \mathrm{g}$ d.w. MDMA was the second most ubiquitous amphetamine-like compound in sludge samples, followed by AM and MA. However, median concentrations were higher for AM (6.6 ng/g d.w.) than for EPH (2.9 ng/g d.w.), MDMA (1.0 ng/g d.w.) and MA (0.2 ng/g d.w.). The occurrence pattern of amphetamine-like compounds in sewage sludge regarding ubiquity and abundance was very similar to that observed in wastewaters surveyed in two of the river basins here investigated, i.e., Ebro [33] and Llobregat [34]. Levels of AM, MA and MDMA were similar to those found by Senta et al. in the particulate phase of activated sewage sludge, which in more cases were below the method LOQ [13]. However, maximum AM levels observed in this study (13.9 ng/g d.w.) were up to one order of magnitude below those reported by Kaleta et al. [14] in biosolids from Austria (300 ng/g d.w.). Note that AM levels of $120 \mathrm{ng} / \mathrm{g} \mathrm{d} . \mathrm{w}$. were found in the sewage sludge employed for method development.

The benzodiazepines ALP and DIA were positively identified in $60 \%$ and $73 \%$ of the investigated samples, respectively, but levels did not surpass $2.5 \mathrm{ng} / \mathrm{g}$ d.w. in any case.

The cumulative amount of target abused and illicit drugs and metabolites in the sewage samples analyzed ranged between 138 and $1560 \mathrm{ng} / \mathrm{g}$ d.w.; the highest levels were observed in the Guadalquivir River basin (see Table S3). Fig. 3 gives a view of the extracted ion chromatograms of the analytes positively identified in one of the investigated sludge samples from the Ebro River basin (E1), where the total drug concentration reached up to $697.4 \mathrm{ng} / \mathrm{g}$ d.w.

\section{Conclusion and remarks}

A multi-residue methodology based on PLE, SPE clean-up and LC-MS/MS analysis was developed for the determination of highly abused licit and illicit drugs and some of their metabolites in sewage sludge. Nine of the 20 target compounds are investigated in this environmental solid matrix for the first time. In spite of the complexity of the sewage sludge samples, reliable determination of 
the target compounds is possible thanks to the use of isotopically labeled analogs as surrogate standards.

The application of the methodology to sewage sludge samples showed that (1) cannabinoids, followed by METH and its metabolite EDDP were the most ubiquitous and abundant compounds in this matrix; (2) HER, 6ACM, LSD and OH-LSD were absent, and (3) cumulative levels of the target analytes in sewage samples reached the $\mu \mathrm{g} / \mathrm{g}$ d.w. level. This work confirms the hypothesis that cannabinoids, i.e., THC, CBD and CBN, accumulate in sewage sludge, as suggested by their non-polar character $(\log$ Kow $>3$ ).

Further application of the treated sewage sludge in agriculture may contribute to transfer these compounds to surface and groundwaters and thus, to re-introduce them in the water cycle and eventually in the food chain. Desorption and time dependent biotic and abiotic degradation processes of these compounds in soils are basically unknown, and will differ between compounds and type of soils. Some work has been carried out in this field for amphetamine-like compounds [35-37]. However, the investigation of the behavior of the most ubiquitous and abundant compounds in sewage sludge, i.e., cannabinoids, is essential in order to correctly assess their environmental risk.

\section{Acknowledgments}

This work has been financially supported by the EU through the EU FP7 project SOLUTIONS (603437), by the Spanish Ministry of Economy and Competitiveness through the project SCARCE (Consolider-Ingenio 2010 CSD2009-00065) and by the Generalitat de Catalunya (Consolidated Research Group: Water and Soil Quality Unit 2009-SGR-965). It reflects only the author's views. The Community is not liable for any use that may be made of the information contained therein. Merck and Biotage are acknowledged for the gift of LC columns and SPE cartridges, respectively. Nicola Mastroianni acknowledges the JAE Program (CSIC-European Social Funds).

\section{Appendix A. Supplementary data}

Supplementary data associated with this article can be found, in the online version, at http://dx.doi.org/10.1016/ j.chroma.2013.10.078.

\section{References}

[1] N.S. Thomaidis, A.G. Asimakopoulos, A.A. Bletsou, Global NEST J. 14 (2012) 72.

[2] S. Castiglioni, E. Zuccato, Philos. Trans. R. Soc. A 367 (2009) 3965.

[3] R. Pal, M. Megharaj, K.P. Kirkbride, R. Naidu, Sci. Total Environ. 463-464 (2013) 1079.

[4] S. Castiglioni, E. Zuccato, in: E. Castiglioni, R. Zuccato, Fanelli (Eds.), Illicit Drugs in the Environment: Occurrence, Analysis, and Fate Using Mass Spectrometry, John Wiley \& Sons, Inc., Hoboken, NJ, 2011, p. 137.

[5] B. Kasprzyk-Hordern, in: S. Castiglioni, E. Zuccato, R. Fanelli (Eds.), Illicit Drugs in the Environment: Occurrence, Analysis, and Fate Using Mass Spectrometry, John Wiley \& Sons, Inc., Hoboken, NJ, 2011, p. 153.
[6] C. Postigo, M. López de Alda, D. Barcelò, in: S. Castiglioni, E. Zuccato, R. Fanelli (Eds.), Illicit Drugs in the Environment: Occurrence, Analysis, and Fate Using Mass Spectrometry, John Wiley \& Sons, Inc., Hoboken, NJ, 2011, p. 115.

[7] C. Postigo, M.J. Lopez de Alda, D. Barceló, Trends Anal. Chem. 27 (2008) 1053.

[8] R. Bagnati, E. Davoli, in: S. Castiglioni, E. Zuccato, R. Fanelli (Eds.), Illicit Drugs in the Environment: Occurrence, Analysis, and Fate Using Mass Spectrometry, John Wiley \& Sons, Inc., Hoboken, NJ, 2011, p. 53.

[9] A. Jurado, N. Mastroianni, E. Vàzquez-Suñé, J. Carrera, I. Tubau, E. Pujades, C. Postigo, M.L. de Alda, D. Barceló, Sci. Total Environ. 424 (2012) 280.

[10] M.R. Boleda, M. Huerta-Fontela, F. Ventura, M.T. Galceran, Chemosphere 84 (2011) 1601.

[11] D.R. Baker, B. Kasprzyk-Hordern, J. Chromatogr. A 1218 (2011) 7901.

[12] C. Metcalfe, K. Tindale, H. Li, A. Rodayan, V. Yargeau, Environ. Pollut. 158 (2010) 3179.

[13] I. Senta, I. Krizman, M. Ahel, S. Terzic, Anal. Bioanal. Chem. 405 (2013) 3255.

[14] A. Kaleta, M. Ferdig, W. Buchberger, J. Sep. Sci. 29 (2006) 1662.

[15] K.H. Langford, M. Reid, K.V. Thomas, J. Environ. Monit. 13 (2011) 2284

[16] T. Jones-Lepp, R. Stevens, Anal. Bioanal. Chem. 387 (2007) 1173.

[17] A. Jelic, M. Petrovic, D. Barcelo, Talanta 80 (2009) 363.

[18] W. Peysson, E. Vulliet, J. Chromatogr. A 1290 (2013) 46.

[19] UNODC, United Nations Office on Drugs and Crime, World Drug Report 2013 2013, Available from: http://www.unodc.org/unodc/secured/wdr/wdr2013/ Executive_summary.pdf (accessed June, 2013).

[20] HSDB, Hazardous Substances Data Bank [Internet], National Library of Medicine (US), Division of Specialized Information Services. 1986, Bethesda (MD), 1986, Available from: http://toxnet.nlm.nih.gov/cgi-bin/sis/htmlgen?HSDB (accessed June, 2013).

[21] L. Barron, J. Havel, M. Purcell, M. Szpak, B. Kelleher, B. Paull, Analyst 134 (2009) 663.

[22] D. Fytili, A. Zabaniotou, Renewable Sustainable Energy Rev. 12 (2008) 116

[23] C. Postigo, M.J. Lopez De Alda, D. Barcelo, Anal. Chem. 80 (2008) 3123.

[24] Directorate General for Health and Consumer Affairs (DG SANCO), Method validation and quality control procedures for pesticide residues analysis in food and feed. SANCO/12495/2011 Brussels, Belgium, 2011, Available from: http://www.crl-pesticides.eu/library/docs/fv/SANCO12495-2011.pdf (accessed October, 2013).

[25] C. Postigo, M.J. Lopez De Alda, M. Viana, X. Querol, A. Alastuey, B. Artiñano, D. Barcelo, Anal. Chem. 81 (2009) 4382

[26] K. Stein, M. Ramil, G. Fink, M. Sander, T.A. Ternes, Environ. Sci. Technol. 42 (2008) 6415.

[27] M.R. Boleda, M.T. Galceran, F. Ventura, J. Chromatogr. A 1175 (2007) 38.

[28] P. Vazquez-Roig, V. Andreu, C. Blasco, Y. Picó, Anal. Bioanal. Chem. 397 (2010) 2851.

[29] S. Castiglioni, E. Zuccato, C. Chiabrando, R. Fanelli, R. Bagnati, Mass Spectrom. Rev. 27 (2008) 378

[30] J.-D. Berset, R. Brenneisen, C. Mathieu, Chemosphere 81 (2010) 859.

[31] L. Bijlsma, J.V. Sancho, E. Pitarch, M. Ibáñez, F. Hernández, J. Chromatogr. A 1216 (2009) 3078.

[32] Commission Decision 2002/657/EC of 12 August 2002 implementing the Council Directive 96/23/EC concerning the performance of analytical methods and the interpretation of results, Official Journal of the European communities, L 221/8. Available from: http://eur-lex.europa.eu/LexUriServ/LexUriServ.do?uri=OJ:L:2002:221:0008: 0036:EN:PDF (accessed June, 2013), 2002/657/EC.

[33] C. Postigo, M.J. Lòpez de Alda, D. Barceló, Environ. Int. 36 (2010) 75.

[34] C. Postigo, N. Mastroianni, M.J. López de Alda, D. Barceló, in: S. Sabater, A. Ginebreda, D. Barceló (Eds.), The Llobregat: A Story of a Polluted Mediterranean River, Springer-Verlag, Berlin, Heidelberg, 2012, p. 239.

[35] A. Janusz, K.P. Kirkbride, T.L. Scott, R. Naidu, M.V. Perkins, M. Megharaj, Forensic Sci. Int. 134 (2003) 62.

[36] R. Pal, M. Megharaj, K.P. Kirkbride, T. Heinrich, R. Naidu, Chemosphere 85 (2011) 1002.

[37] R. Pal, M. Megharaj, R. Naidu, G. Klass, M. Cox, K.P. Kirkbride, Forensic Sci. Int. 220 (2012) 245. 